\title{
EFFECT OF END CONNECTION RESTRAINTS ON THE STABILITY OF STEEL BEAMS IN BENDING
}

\author{
S. Amara ${ }^{1, *}$, D.E. Kerdal ${ }^{2}$ and J.P. Jaspart ${ }^{3}$ \\ ${ }^{I}$ Department of Civil Engineering, Civil Engineering Laboratory, Laghouat University, Algeria \\ ${ }_{2}^{2}$ Professor,Department of Civil Engineering, LM2SC Laboratory, U.S.T.Oran, Algeria \\ ${ }^{3}$ Professor, ArGEnCo Department, Liège University, 1 Chemin des Chevreuils, Liège, Belgium \\ *(Corresponding author: tel:+213 7761305 51; fax:+213 299326 98; email : slhamara@yahoo.com)
}

Received: 1 June 2008; Accepted: 15 August 2008

\begin{abstract}
The influence of the end restraint conditions on the lateral-torsional buckling of beams is investigated in detail using finite element method. The paper focuses on the limitation of Eurocode 3 regarding the lateral bending and torsional restraint coefficients $\mathrm{k}_{\mathrm{z}}$ and $\mathrm{k}_{\theta}$ of the end supports. Theoretical expressions of the coefficients $\mathrm{k}_{\mathrm{z}}$ and $\mathrm{k}_{\theta}$ taking into account the minor axis flexural restraint at the support and the end torsional restraint respectively are presented. The introduction of new coefficients $k_{z}$ and $k_{\theta}$ representing the actual support conditions in the expression of the elastic critical moment is suggested. A comparison between the elastic critical moments for various beam cross-sections, lengths and various end restraints, obtained from the finite-element method, and those derived from EC3 ENV method, in which the proposed coefficients $k_{z}$ and $k_{\theta}$ are introduced, confirms the reliability of these coefficients that model the end support conditions.
\end{abstract}

Keywords: Elastic lateral-torsional buckling; End restraints; Elastic critical moment; Out-of plane bending; Uniform torsion; Warping

\section{INTRODUCTION}

A slender beam under the action of bending loads in the plane of maximum flexural rigidity can buckle by combined twist and lateral bending of the cross-section, unless it has continuous lateral support. This phenomenon, which was first investigated theoretically and experimentally during the nineteenth century, is known as lateral buckling. Slender beams manufactured from narrow rectangular sections or I-sections with narrow flanges, lack both lateral flexural rigidity and torsional rigidity, and if left unsupported, or supported intermittently only, they may buckle under bending stresses considerably lower than the yield or proof stress of the material. The low torsional rigidity is an important factor, so thin-walled open section beams such as channels or zeds are also susceptible to this form of instability. Box beams on the other hand, which are torsionally stiff and have similar flexural properties about the two principal axes of inertia, are very resistant to lateral buckling. The elastic buckling stress is also influenced by the conditions of support at the ends of the beam, and by the type and position of the applied loads that cause bending. In thin-walled open sections the point of application of the load with respect to the shear centre is important, and for all types of sections initial imperfections can influence the behaviour, particularly of members of intermediate length.

Research developments on lateral torsional buckling of steel members have been accompanied by the realization of updated design codes and standards. Modern steel codes for structures, such as AISC LRFD [1, 2], BS 5950-1 [3] and EC3 [4, 5], provide, on the basis of the limit state concept, design procedures to compute the lateral-torsional buckling resistance of beams. Primary, these procedures generally require the determination of the elastic critical buckling moment. Initial imperfections, residual stresses and inelastic buckling are taken into account through the use of buckling curves [6]. 
The elastic critical moment is directly dependent on the following factors [7]: material properties such as the modulus of elasticity and shear modulus; geometric properties of the cross-section such as the torsion constant, warping constant, and moment of inertia about the minor axis; properties of the beam such as length, and lateral bending and warping conditions at supports; and finally loading, since lateral-torsional buckling is greatly dependent on moment diagram and loading position with respect to the section shear centre. The bending moment diagram is taken into account by means of the equivalent uniform moment factor $C_{1}$. The elastic critical moment of a simply supported beam with uniform moment is multiplied by the equivalent uniform moment factor $C_{1}$ to obtain the elastic critical moment for any bending moment diagram.

Lateral bending and torsional restraints provided by beam end supports have a significant effect on the lateral torsional buckling of beams. The degrees of lateral bending and torsional restraints developed by the supports depend on the type of the connection used. Many simple connections met in practice have only partial lateral bending restraint and are generally assumed to provide full torsional restraint. However, some connections such as long fin-plate connections provide both partial lateral bending and torsional restraints. Therefore, the beams connected with fin-plates are prone to undergo some twisting about the longitudinal axis at the supports, in addition to lateral bending. EC3 $\mathrm{ENV}^{*}$ takes into account the effect of the lateral bending restraint of the end support in the evaluation of the elastic critical moment $M_{c r}$ by means of a coefficient $k_{z}$. However, it is assumed that full torsional restraint is provided by the connection.

For any particular end connection, the influence of the degree of lateral bending and torsional restraints can be expressed in terms of reduction of the lateral torsional bending moment $M_{c r}$. The scope of this work is to study the effects of lateral and torsional end restraints on the lateral torsional buckling moment of the beam. An analytical model has been developed in order to evaluate the lateral bending and the torsional restraints coefficients $k_{z}$ and $k_{\theta}$. The model also allows to evaluate the percentage of reduction of the lateral torsional bending moment $M_{c r}$ against $M_{0 c r}$ for full restraint. On the basis of the value of the percentage reduction of $M_{c r}$ for a particular connection, its classification as simple, partial restraint or full restraint can be made. Therefore, it is possible using the analytical model developed to determine the required lateral bending and torsional restraints of the connection to ensure full lateral restraint.

Theoretical expressions of the coefficients $k_{z}$ and $k_{\theta}$, taking into account the support minor axis bending and the torsional restraints respectively are proposed. A variety of connections with different end restraints are investigated using the finite element software LTBeam [8] in order to determine their influence on the lateral torsional buckling critical moment. It should be noted that this research work is of theoretical nature. It is done for three simple load cases. A uniform distributed load, acting on the beam in the vertical direction at the shear centre, a constant moment along the beam and a concentrated load at mid-span acting at the shear centre. A comparison between the elastic critical moments for various beam lengths and various end restraints, obtained from LTBeam, and those derived from the EC3 ENV formula in which the coefficients $k_{z}$ and $k_{\theta}$ computed from the proposed formulae are introduced, confirms the reliability of these coefficients that model end support conditions.

\footnotetext{
${ }^{*}$ Reference is made to EC3 ENV [5] and not to EC3 EN [4] as the formulae for $\mathrm{M}_{\mathrm{cr}}$ have been removed from [4] in the so-called "conversion period"
} 
Given the type of loading, Eurocode 3 [5] provides the values of the equivalent uniform moment factor $\mathrm{C}_{1}$ only for limited end restraints conditions for $k_{z}=1$ and $k_{z}=0,5$. In the cases of the lateral bending coefficients $k_{z}$ being different from 1,00 and 0,5 the corresponding values of $C_{1}$ have been obtained by linear interpolation.

\section{LATERAL TORSIONAL BUCKLING AND ELASTIC CRITICAL MOMENT}

Under increasing loading (see Figure 1), the beam first bends strictly in the plane of loading and w is the deflection in that plane. Once the moment reaches a certain magnitude $M_{c r}$, called elastic critical moment, the beam may deflect suddenly out of the plane of bending. This instability phenomenon is known as lateral torsional buckling. Lateral torsional buckling is said to occur by bifurcation of equilibrium. The beam simultaneously exhibits lateral displacements $\mathrm{v}$ in the $\mathrm{y}$ direction (bending about the minor axis of the cross-section) and twist rotation $\theta$ about its longitudinal axis $\mathrm{x}$.

It is clear that lateral-torsional buckling is resisted by a combination of lateral bending resistance $E I_{z} d^{2} v / d x^{2}$ and torsional resistances $G I_{t} d^{2} \theta / d x^{2}$ and $E I_{w} d^{3} \theta / d x^{3}$. Thus, a member is especially prone to lateral torsional buckling when it has low lateral flexural stiffness $E I_{z}$ and its torsional stiffness $G I_{t}$ and warping stiffness $E I_{w} / L^{2}$ are low compared to its stiffness in the plane of loading. With the nomenclature used in Eurocode 3 [4], where $(x-x)$ is the axis along the member, (y-y) is the major axis of cross-section and (z-z) is the minor axis of the cross-section, the governing differential equation for the lateral torsional buckling is [7]:

$$
E I_{w} \frac{d^{4} \phi}{d x^{4}}-G I_{t} \frac{d^{2} \phi}{d x^{2}}-\frac{1}{E I_{z}} M_{y}^{2} \phi+\frac{1}{E I_{z}} M_{y} M_{z}=0
$$

with

$$
\frac{d M_{y}}{d x}=V_{z} ; \frac{d V_{z}}{d x}=-q_{z} ; \frac{d M_{z}}{d x}=-V_{y} ; \frac{d V_{y}}{d x}=0
$$

where $q_{z}$ is the distributed load acting on the beam, $V_{y}$ and $V_{z}$ are the shear forces, $M_{y}$ and $M_{z}$ are the bending moments, and $\phi$ is the torsion deformation. In order to be able to impose appropriate boundary conditions at supports, the internal shear forces and the bending moment components in Eqs. (1) and (2) are referred to the axis in the undeformed configuration.

Exact solutions for Eq. 1 are obtained for a doubly symmetrical beam with simply supported conditions, free warping and subjected to a uniform moment diagram. The elastic critical moment for this basic case is:

$$
M_{c r}=\frac{\pi^{2} E I_{z}}{L^{2}} \sqrt{\frac{I_{w}}{I_{z}}+\frac{L^{2} G I_{t}}{\pi^{2} E I_{z}}}
$$

The elastic critical moment obtained for the basic situation by formula (3), is multiplied by the equivalent uniform moment factor $C_{1}$ which takes into account the actual bending moment diagram. Thus, the value of $M_{c r}$ may be computed by the expression: 
$M_{c r}=C_{1} \frac{\pi^{2} E I_{z}}{\left(k_{z} L\right)^{2}} \sqrt{\left(\frac{k_{z}}{k_{w}}\right)^{2} \frac{I_{w}}{I_{z}}+\frac{\left(k_{z} L\right)^{2} G I_{t}}{\pi^{2} E I_{z}}}$

where the lateral bending coefficient $k_{z}$ and the warping coefficient $k_{w}$ are introduced in order to take into account support conditions other than simply supported. These coefficients are equal to 1,00 for free lateral bending and free warping and 0,5 for prevented lateral bending and warping.

\subsection{Eurocode 3 (ENV) Approach and Its Limitations}

The assessment of the stability behaviour of steel beams based on simplified calculations, as described in the standards of most countries, is not always a realistic evaluation. The assumption that member end connections behave as either pinned or completely rigid is a highly simplified approach because experimental investigations show that true joint behaviour has characteristics between these two simplified extremes. In order to simplify the calculation of structural elements, beams or girders and columns are treated in isolation in most steel design codes, and the effect of the connections is estimated using simple factors which take account of the warping and bending restraint conditions.

The design proposals for the buckling of beams assume that the end supports should completely prevent end twisting. If the supports have only limited elastic torsional restraint stiffness, the beam will buckle at a lower load than that estimated from the idealised case (Figure 1).

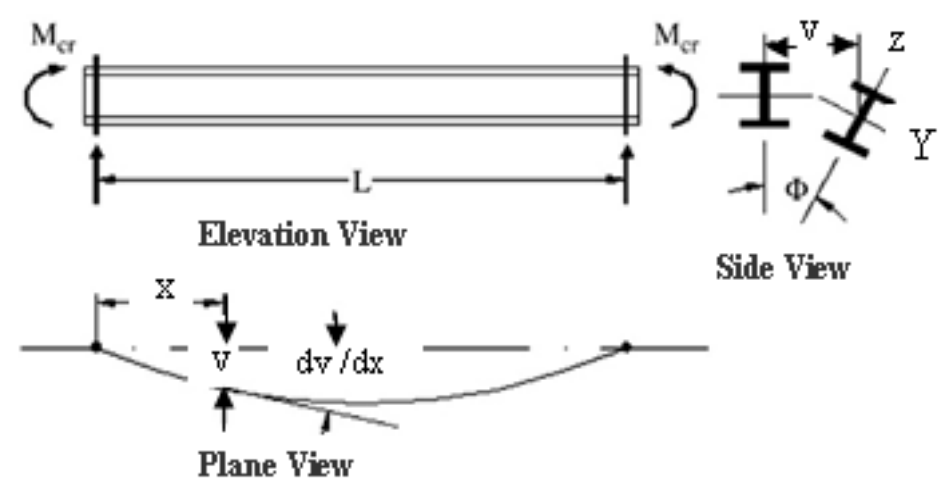

Figure 1. Buckling of a Simply Supported I-beam

One of the most commonly employed general formulae to estimate elastic critical moment $\mathrm{M}_{\mathrm{cr}}$ is the so-called 3-factor formula, which was included in the ENV version of EC3 [5]. The recently completed EN version of this design standard [4] provides no information concerning the determination of $M_{c r}$. In theory, this formula should be applicable to beams subjected to major axis bending having doubly or singly symmetrical cross-sections and arbitrary support and loading conditions. However, some particular cases are currently not covered, most notably the case of beams with partial end restraint against minor axis bending, and partial end restraint against twisting, which are in practice partially free to deflect laterally and twist at the supports.

The moment gradient along the beam is considered by the use of the coefficient $C_{1}$ which is also affected by the lateral bending conditions at end supports. Eq. 4 gives the elastic critical moment as a function of $C_{1}, k_{z}$ and $k_{w}$. It can be seen from the $\mathrm{M}_{\mathrm{cr}}$ expression Eq. 4, that the effect of the end twisting at the supports of the beam which is supposed to be introduced by a coefficient $k_{\theta}$ has not been taken into account. This means that the beam is assumed to be completely prevented 
from twisting about the longitudinal axis at the end supports. However, many real situations met in practice are not in compliance with these standard conditions. For these practical situations (such as those with simple connections with long fin-plates which possess partial torsional restraint), the beam is prone to undergo some twisting about the longitudinal axis at the end supports causing a deduction in elastic critical moment $\mathrm{M}_{\mathrm{cr}}$. Therefore the effect of the partial end torsional restraint should be considered by introducing a coefficient $k_{\theta}$ in the expression of $\mathrm{M}_{\mathrm{cr}}$.

This paper attempts to fill in two of the insufficiencies identified in the above expression of $M_{c r}$ used by the Eurocode 3, by (i) proposing a formula for computing the value of the lateral bending restraint coefficient $k_{z}$ which depends on both the connection end restraint and the beam flexural stiffness about the minor axis and (ii) proposing a formula for computing the value of the torsional restraint coefficient $k_{\theta}$ of the end support (Figure 2) which depends on both the torsional stiffness of the support $K_{\Theta}$ and of the torsional rigidity of the beam $G I_{t} / L$.

In the EC3 ENV [5], it is suggested to take $k_{w}=1,00$ unless special provision for warping fixity is made. Therefore, in this paper, the warping coefficient $k_{w}$ is set to be equal to 1,00 .

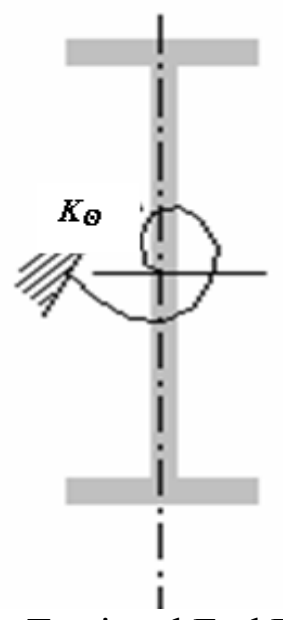

Figure 2. Torsional End Restraint

\subsection{Theoretical Background on Torsional Restraints at Supports}

Flint [9] presented an analysis for a member with end connections providing only limited torsional stiffness. For a beam under single point load or two symmetrical point loads, Flint derived the following relationship between the critical load and the support torsional restraint stiffness.

$m=1-\frac{4}{3} R_{T}$

In Eq. $5 \mathrm{~m}$ is the ratio between buckling loads for beams with finite and infinite support torsional stiffness. $R_{T}$ is the ratio of the torsional stiffness of the beam to its supports and is given by $\frac{G J / L}{T / \theta}$ where $\theta$ is the rotation of a support.

A theoretical study was carried out by Schmidt [10] to determine the effect of elastic end torsional restraint on the critical load of a beam. It shows that the beam is incapable of supporting any load if the end supports offer no resistance to end twisting. It further shows that the critical load increases 
little as the end torsional restraint stiffness parameter $e$ increases beyond 20. The parameter $e$ is defined as $e=1 / R_{T}$. According to Flint's equation (5), Bose [11] found that the critical load for $e=20$ will be $93 \%$ of the load for rigid torsional end support.

Bennetts et al [12] and Grundy et al [13] have attempted to investigate the value of the torsional stiffness $K$ of an end restraint and in particular, the torsional stiffness $K_{s}$ of the connection component. They investigated the behaviour of fin-plates and noted that the torsional stiffness varied almost continuously with the applied moment.

Bennetts et al stated that the end torsional stiffness is a function of the beam web thickness, the depth of the beam and the depth of the connection component. They felt that the interaction between these components is quite complex and attempts to produce a theoretical model for the overall behaviour would probably prove unsuccessful. They also found that the experimental results were sensitive to the method of testing and results differed in subsequent loading cycles. However, it is worth noting that the test rig used produced only a torsional moment in the fin-plate connection. This method of testing removed any possibility of beneficial restraining effects afforded by the supported beam upon the connection.

\section{PARAMETRICAL STUDY ON BEAM ELASTIC STABILITY}

As seen before, the elastic critical moment $\mathrm{M}_{\mathrm{cr}}$ is a function of $C_{1}, k_{z}$ and $k_{w}$. It should be noted that the design proposals for the buckling of beams EC3 does not consider the possibility of $k_{z}$ being different from 1,00 or 0,5 which represent the two extreme cases, free lateral bending and prevented lateral bending. In practice, the coefficient $k_{z}$ may take any value between 1,00 and 0,5 depending on the degree of lateral restraint provided by the end supports of the beam. It should also be mentioned that EC3 ENV does not take into account the possibility of the end restraint being partially prevented from twisting about the longitudinal axis of the beam. The elastic critical moment expression considers the beam as completely prevented from twisting at the end supports. If the supports have only limited elastic torsional restraint stiffness, as it is the case of some practical connections such as fin-plates, the beam will buckle at a lower load than that estimated from the idealised case. Therefore, the aim of this work is to derive analytical expressions for the lateral bending restraint at the support $k_{z}$ and the torsional end restraint $k_{\theta}$ to be introduced in the expression of the elastic critical moment $M_{c r}$.

\subsection{Proposed Expressions of Lateral and Torsional Restraint Coefficients at Supports}

The behaviour of beams is dependent on their end support conditions and possibly on their intermediate supports. These conditions depend not only on major axis bending (primary bending) but also on minor axis bending, uniform torsion and warping torsion. The latter three types of support conditions influence deeply the LTB resistance. In the existing codes, the support conditions are accounted for by means of so-called effective length factors $k_{z}$ and end warping factor $k_{w}$. Each of these two factors varies from 0,5 for full fixity to 1,00 for no fixity at all, and takes the value of about 0,7 for one end fixed and one end free. In the EC3 ENV [5], it is suggested to take $k_{w}=1,0$ unless special provision for warping fixity is made. The values of the $C_{1}$ factor involved in the analytical expression of the elastic critical LTB moment is significantly influenced by the $k_{z}$ values; however, in EC3 ENV, only 2 or 3 values of $k_{z}$ are suggested. In order to be 
able to evaluate satisfactorily the values of $k_{z}$, it is probably acceptable to calculate the $\mathrm{C}_{1}$ factor by means of linear interpolation.

Different expressions for computing lateral bending restraint coefficient $k_{z}$ and torsional restraint $k_{\theta}$ of the end support have been considered, and the following ones Eq. 6 and Eq. 7 are finally selected, even though further research might provide a more exact formulation.

$k_{z}=\frac{E I_{z} / L+0,25 K_{v^{\prime}}}{E I_{z} / L+0,5 K_{v^{\prime}}}$

$k_{\theta}=\sqrt{1+5 \frac{G I_{t} / L}{K_{\Theta}}}$

where: $I_{z}$ is the minor axis moment of inertia of the beam, $E$ is the modulus of elasticity, $\mathrm{L}$ is the unbraced length, $K_{v^{\prime}}$ is the lateral flexural restraint of the support, $G$ is the shear modulus, $I_{t}$ is the torsional constant and $K_{\Theta}$ is the torsional restraint of the support .

It can be seen from Eq. 6 that for $K_{v^{\prime}}$ varying from zero to infinity, the value of $k_{z}$ ranges from 1,00 (no fixity) to 0,5 (full fixity). Eq. 7 shows that if no torsional restraint is provided by the support $\left(K_{\Theta}=0\right)$, then the torsional restraint coefficient $k_{\theta}$ is infinity, and for full torsional restraint of the support ( $K_{\Theta}=$ infinity), the torsional restraint coefficient $k_{\theta}$ is 1,00 .

For doubly symmetrical cross-section and for end moment loading or transverse loads applied at the shear centre, the elastic critical moment to be considered as the critical value of the maximum moment in the beam may be assessed by the new proposed formula:

$M_{c r}=C_{1} \frac{\pi^{2} E I_{z}}{\left(k_{\theta} k_{z} L\right)^{2}} \sqrt{\left(\frac{k_{\theta} k_{z}}{k_{w}}\right)^{2} \frac{I_{w}}{I_{z}}+\frac{\left(k_{\theta} k_{z} L\right)^{2} G I_{t}}{\pi^{2} E I_{z}}}$

where $k_{z}$ is the lateral bending restraint coefficient, ranging from 0,5 (for full fixity) to 1,00 (for free lateral bending at the support), which can be evaluated from Eq. $6, k_{\theta}$ is the torsional restraint coefficient which varies from 1,00 (for support prevented from twisting about longitudinal axis) to infinity (for free twisting of the support about longitudinal axis).

Eq. 8 may be written in its simplified form as:

$M_{c r}=C_{1} \frac{\pi^{2} E I_{z}}{k_{\theta}\left(k_{z} L\right)^{2}} \sqrt{\left(\frac{k_{z}}{k_{w}}\right)^{2} \frac{I_{w}}{I_{z}}+\frac{\left(k_{z} L\right)^{2} G I_{t}}{\pi^{2} E I_{z}}}$

It can be seen that Eq. 9 is the same as the one given by EC3 ENV [5], only for a beam fully prevented from twist rotation at the supports $\left(k_{\theta}=1\right)$. It can also be seen from Eq. 9 that for a support connection providing no torsional restraint $\left(k_{\theta}=\right.$ infinity), the elastic critical moment $M_{c r}$ tends towards zero and therefore the beam will be in the state of instability. 
Finally Eq. 9 can be expressed as:

$$
M_{c r}=\frac{1}{k_{\theta}} M_{0 c r}
$$

It can be seen from Eq. 10, that the critical moment $M_{c r}$ can be obtained by multiplying the critical moment $M_{0 c r}$ obtained for a beam with full torsional restraint at supports $\left(k_{\theta}=1\right)$ by $\frac{1}{k_{\theta}}$.

\section{ANALYTICAL EVALUATION OF THE ELASTIC STABILITY}

\subsection{Influence of Lateral Bending Restraint}

In this section the variation of the lateral bending restraint coefficient $k_{z}$ is examined for various sizes of IPE profiles (IPE300, IPE360, IPE400 and IPE500) of varying lengths ( $\mathrm{L}=4 \mathrm{~m}, 6 \mathrm{~m}, 10 \mathrm{~m}$, and $12 \mathrm{~m}$ ), subjected to three load cases, equal end moments, uniformly distributed vertical loads applied to the shear centre and a concentrated vertical load at mid-span applied to the shear centre.

In order to perform a comparative study, numerical analysis was conducted using the LTBEAM software which was developed by CTICM [8] within the framework of a European project and based on the finite element method. In this analysis the end supports of the beam are assumed to be fixed for out of plane deflection, $v=0$ and twist rotation, $\theta=0\left(k_{\theta}=1\right)$, but not restrained against warping, $\left(k_{w}=1\right)$. The lateral flexural restraint of the support is modelled by a spring of lateral restraint value $K_{v^{\prime}}$. It is taken as zero (for no lateral restraint) or infinity (for full lateral restraint). To evaluate $M_{c r}$ using the FEM, it is necessary to determine the value of the lateral bending restraint of the connection $K_{v^{\prime}}$. Therefore, for any lateral bending restraint coefficient $k_{z}$, the corresponding value of $K_{v^{\prime}}$ can be evaluated using Eq. 6 .

Figure 3 shows the numerical and analytical results of the variation of elastic critical moment against variation of lateral bending restraint coefficient $k_{z}$ for equal end moments. It can be seen from Figure 3 that the results obtained from EC3 ENV formula for $k_{z}$ varying from 0,5 to 1,00 are in very good agreement with those computed from FEM, except for the case of full lateral restraint. For $k_{z}=0,5$, the values of $M_{c r}$ obtained from EC3 ENV formula are lower than those derived from FEM.

The reason is that the EC3 ENV formula assumes that coefficient $C_{1}$ does not vary with end support conditions for equal end moments. However, using finite differences approach, Miguel A. Serna [7] shows that for the case of equal end moments, the values of $C_{1}$ for beams with prevented lateral bending at supports $\left(k_{z}=0.5\right)$ are higher than those for simply supported beams, which confirms the difference found in this study between the numerical and analytical results of $M_{c r}$ for the case of restrained end supports against lateral bending $\left(k_{z}=0,5\right)$. Following the difference between the FEM results and those obtained analytically by EC3 ENV formula, for $k_{z}=0,5$ it is recommended that the value of $C_{1}$ be taken as 1,05 which is the value suggested in [14]. 


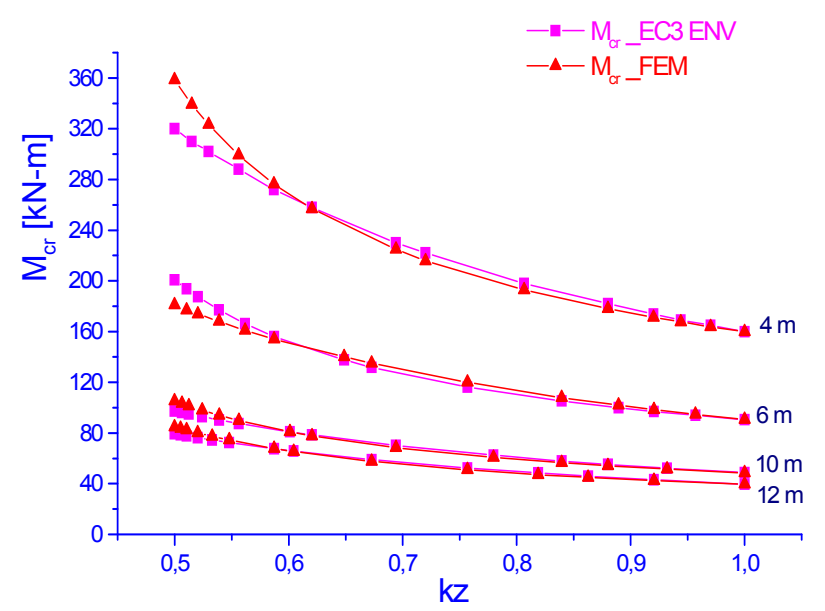

(a) Results for IPE 300

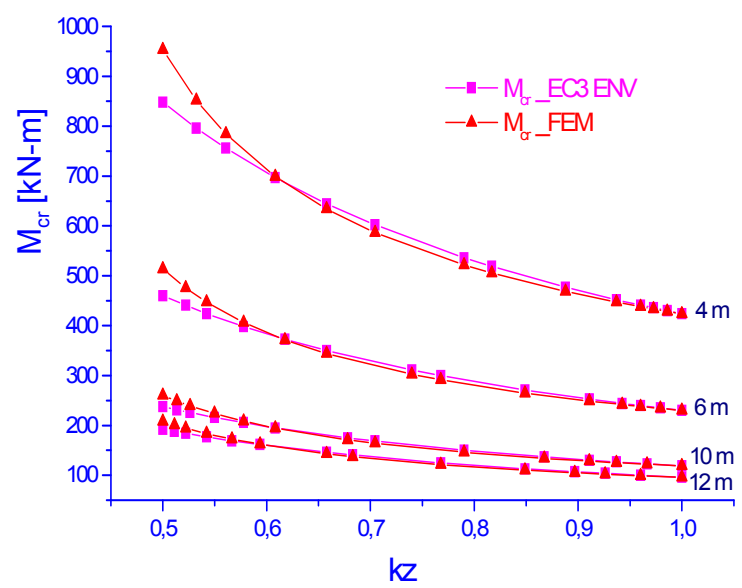

(c) Results for IPE 400

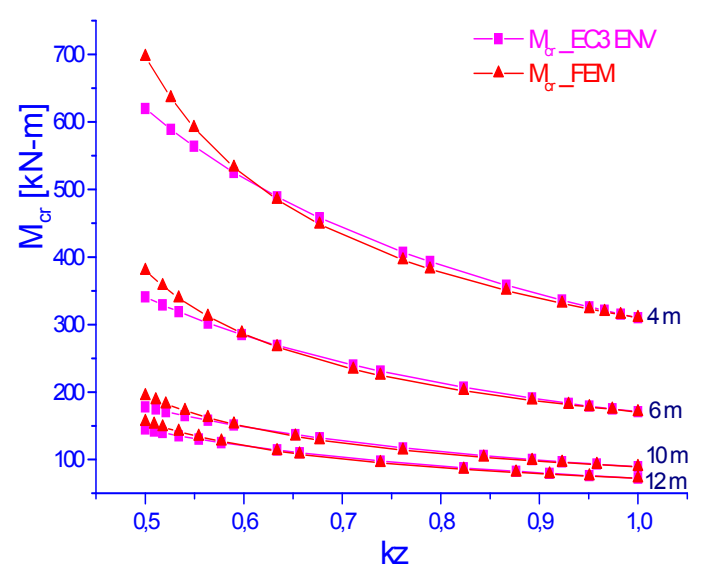

(b) Results for IPE 360

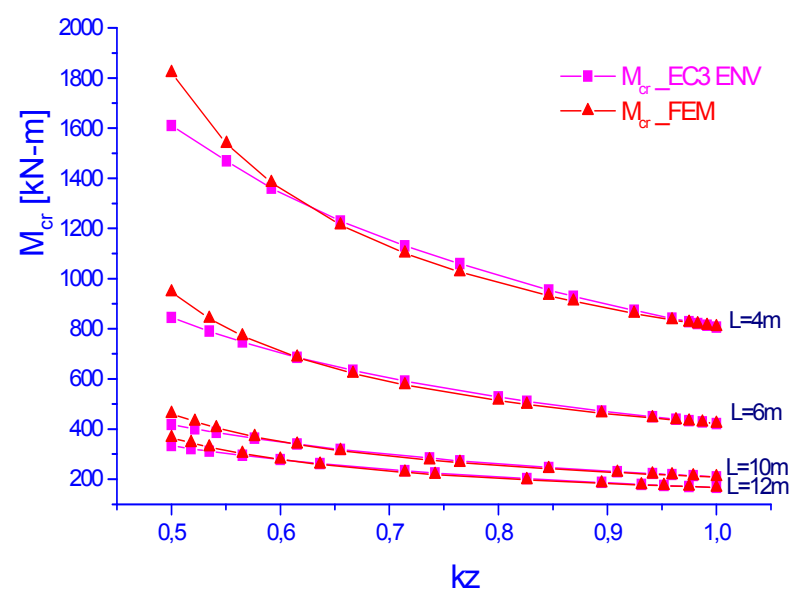

(d) Results for IPE 500

Figure 3. Numerical and Analytical Elastic Critical Moments Versus Lateral Bending Coefficient $k_{z}$ for Equal End Moments

For the case of uniformly distributed vertical loads, the numerical and analytical results of the variation of elastic critical moment $M_{c r}$ as a function of lateral bending restraint coefficient $k_{z}$ are given in Figure 4. 




(a) Results for IPE 300

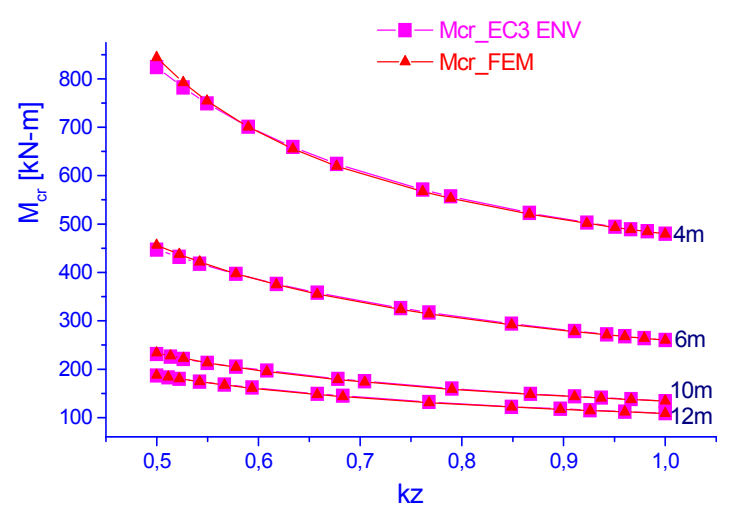

(c) Results for IPE400

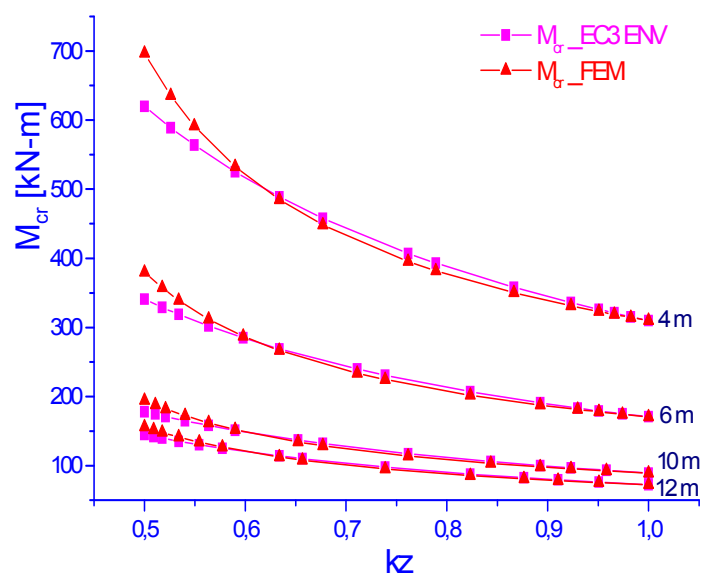

(b) Results for IPE360

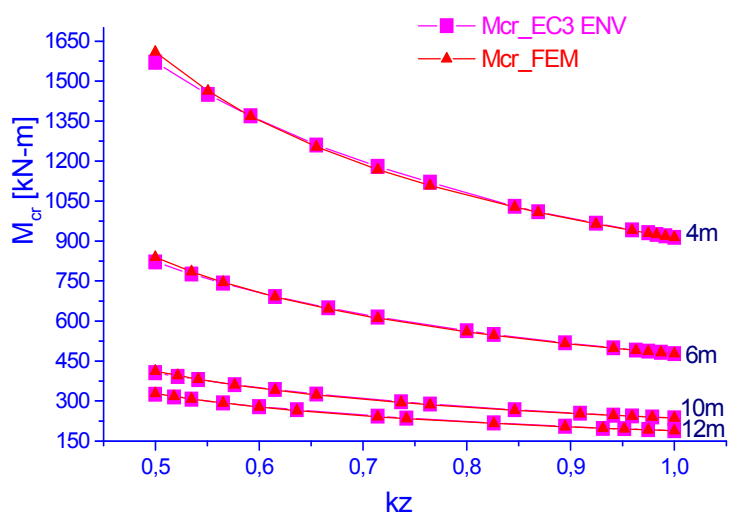

(d) Results for IPE500

Figure 4. Numerical and Analytical Elastic Critical Moments Versus Lateral Bending Coefficient $k_{z}$ for Uniformly Distributed Loads

It can be seen that for all IPE profiles and beam lengths considered in this study, there is quite good agreement between the values given by the EC3 ENV formula and the numerical results obtained using the finite elements approach.

Finally, Figure 5 shows the results of the variation of elastic critical moment $M_{c r}$ against lateral bending restraint coefficient $k_{z}$ for the case of concentrated load acting at the mid span. As can be seen from Figure 5, the graphs of the elastic critical moments $M_{c r}$ obtained analytically for various IPE profiles and lengths are very close to those computed numerically by the finite element method. Therefore the proposed new formula (6) provides very good approximation of $k_{z}$ for all cases considered in this study. 


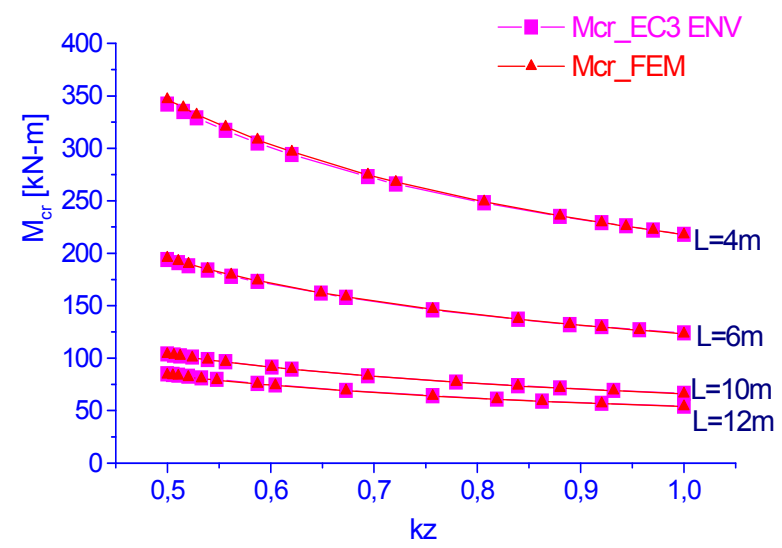

(a) Results for IPE300

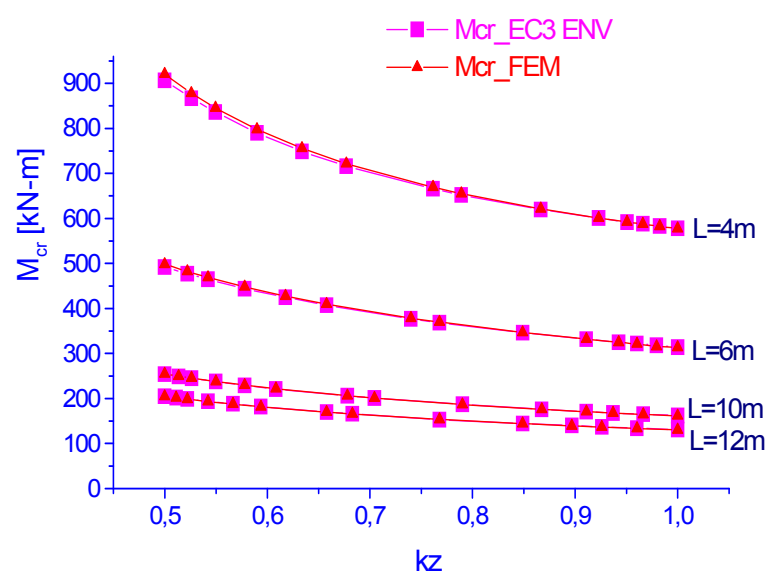

(c) Results for IPE400

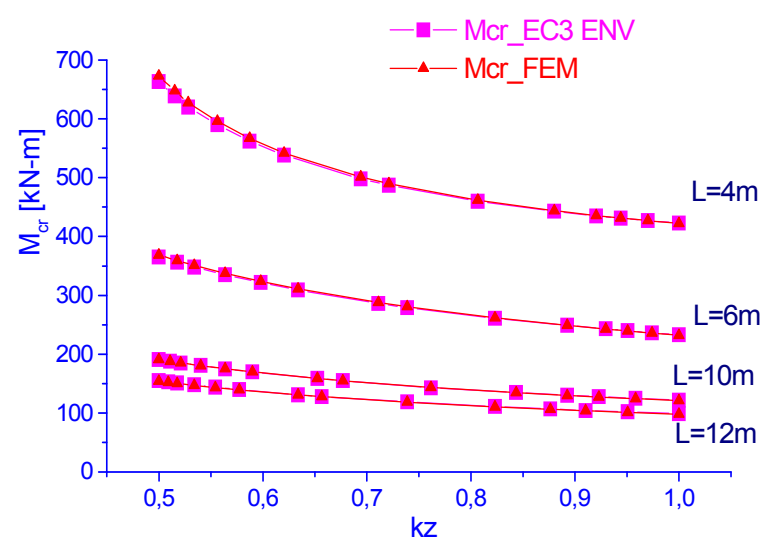

(b) Results for IPE360

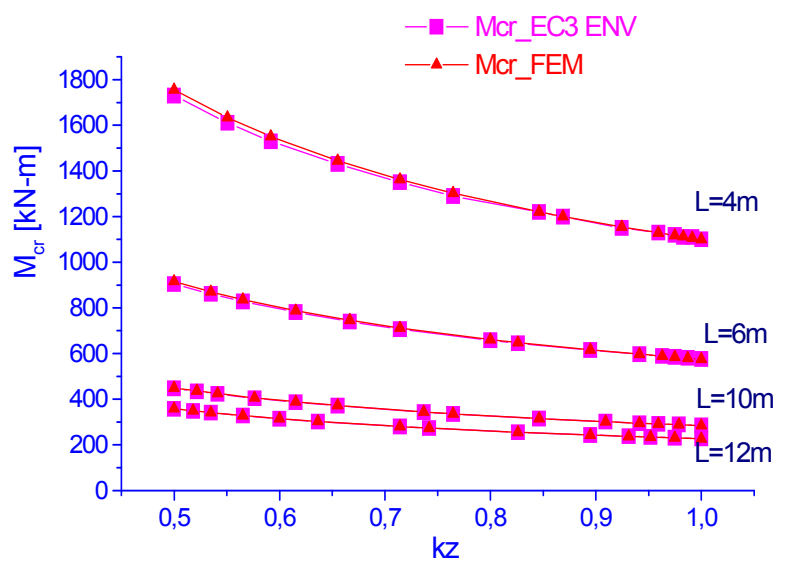

(d) Results for IPE 500

Figure 5. Numerical and Analytical Elastic Critical Moments Versus Lateral Bending Coefficient $k_{z}$ for a Concentrated Load at the Mid Span

\subsection{Influence of End Torsional Restraint}

In this study, the effect of the variation of support torsional restraint $k_{\theta}$ on the elastic critical moment $M_{c r}$ is investigated numerically using finite element approach and analytically with the application of the EC3 ENV formulation. As mentioned previously, the elastic critical moment $M_{c r}$ for a beam determined according to EC3 ENV formula, assumes that the end supports of the beam are fully prevented from twisting, thus full torsional restraint is provided. However, some types of supports met in practice such as fin-plates, provide only partial torsional restraint. Therefore it is recommended that the effect of torsional restraint provided by end supports of the beam should be taken into account in the EC3 ENV formula by means of a coefficient $k_{\theta}$. The values of $k_{\theta}$ may be obtained using the proposed formula (7).

The lateral-torsional buckling of four IPE profiles (IPE 300, IPE 360, IPE 400 and IPE 500) with three different lengths $(\mathrm{L}=6 \mathrm{~m}, \mathrm{~L}=10 \mathrm{~m}$ and $\mathrm{L}=12 \mathrm{~m}$ ) have been studied for two load cases, uniformly distributed vertical loads applied to the shear centre and a concentrated vertical load at mid-span 
applied to the shear centre. In this analysis the end supports of the beam are assumed to be fixed for out of plane deflection $(v=0)$ and for lateral bending rotation $\left(k_{z}=1\right)$ but not restrained against warping $\left(k_{w}=1\right)$. The torsional restraint of the support is modelled by a spring of torsional restraint value $K_{\Theta}$. If no torsional restraint is provided by the support $\left(K_{\Theta}=0\right)$ then $\frac{1}{k_{\theta}}=0$ and for full torsional restraint of the support ( $K_{\Theta}=$ infinity) then $\frac{1}{k_{\theta}}=1$. For partial torsional restraints of the end supports, which correspond to the values of $\frac{1}{k_{\theta}}$ varying from 0 to 1,00 , the corresponding values of the spring torsional restraints $K_{\Theta}$ can be calculated from Eq. 7 .

Figure 6 shows the numerical and analytical results of the variation of $M_{c r} / M_{0 c r}$ against variation of $\frac{1}{k_{\theta}}$ for the case of uniformly distributed vertical loads. According to Eq. 10, the graphs of $M_{c r} / M_{0 c r}$ versus $\frac{1}{k_{\theta}}$ for all IPE cross-sections and lengths obtained from the analytical expression through the application of the new proposed formula are represented by a single straight line. It can be seen from Figure 6 that the numerical results of $M_{c r} / M_{0 c r}$ against $\frac{1}{k_{\theta}}$ obtained through LTBEAM software in which the values of the spring torsional restraints $K_{\Theta}$ are computed from the proposed analytical formula (7), are represented by curved lines.

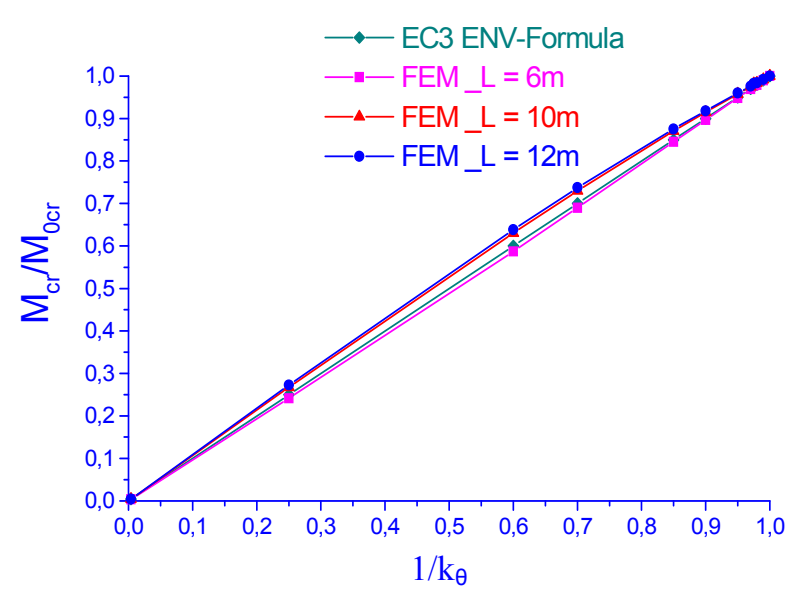

(a) Results for IPE 300

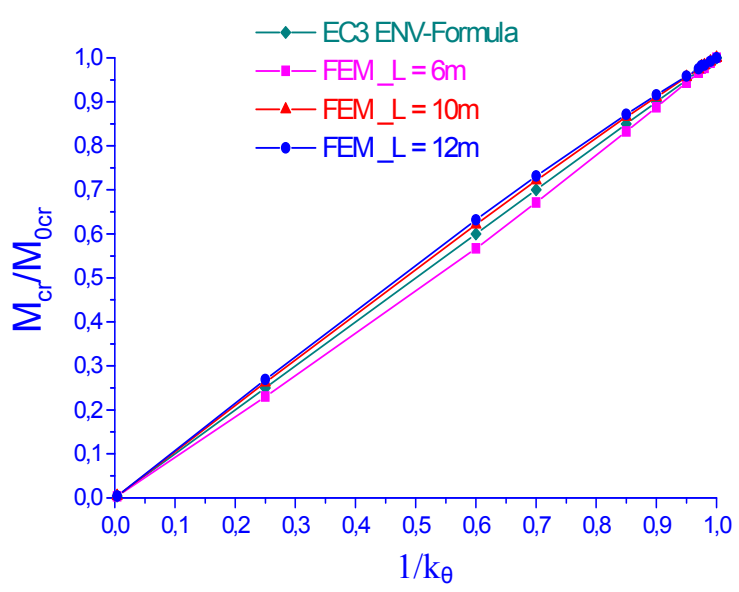

(b) Results for IPE 360 


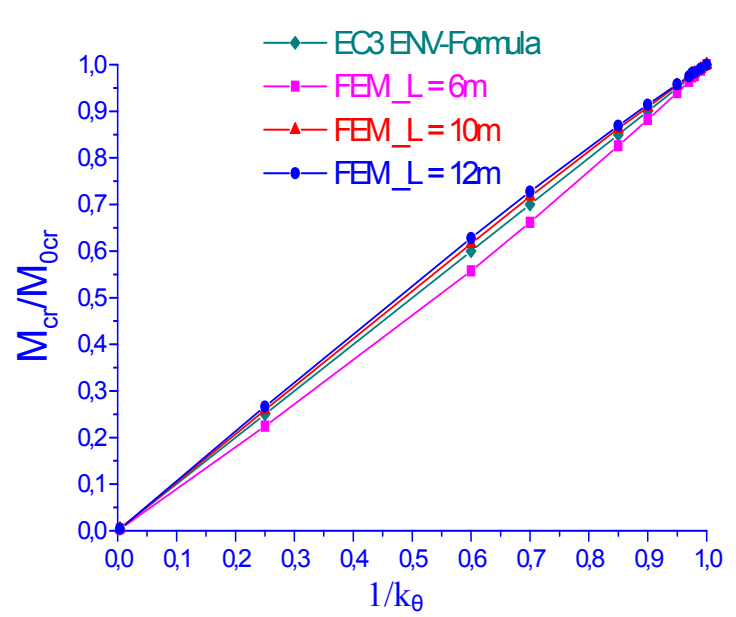

(c) Results for IPE400

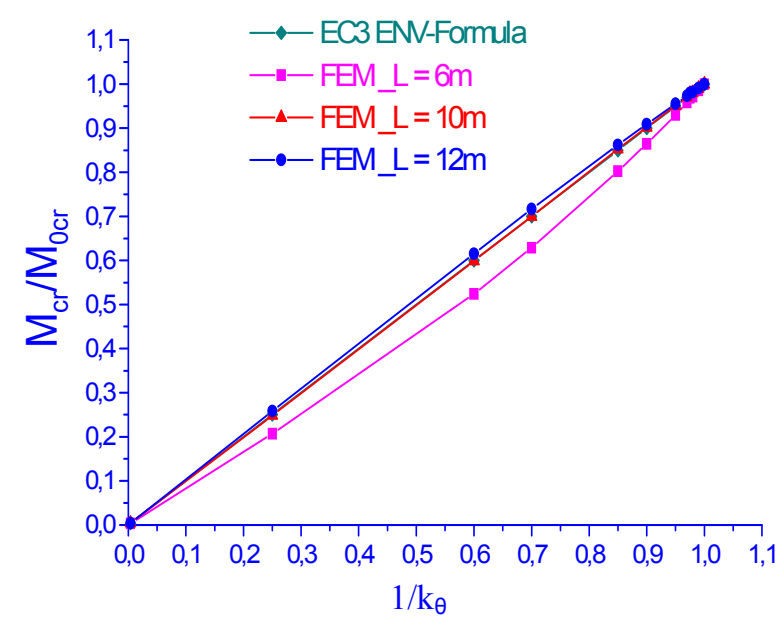

(d) Results for IPE 500

Figure 6. Results from FEM and Eq. 10 for uniformly distributed loads

Figure 7 shows the numerical and analytical results of the variation of $M_{c r} / M_{0 c r}$ against variation of $\frac{1}{k_{\theta}}$ for the case of a concentrated vertical load at the mid-span acting at the shear centre. Again it also shows that the numerical results of $M_{c r} / M_{0 c r}$ against $\frac{1}{k_{\theta}}$ obtained through LTBEAM software in which the values of the spring torsional restraints $k_{\Theta}$ are computed from the proposed analytical formula (7) are represented by curved lines.

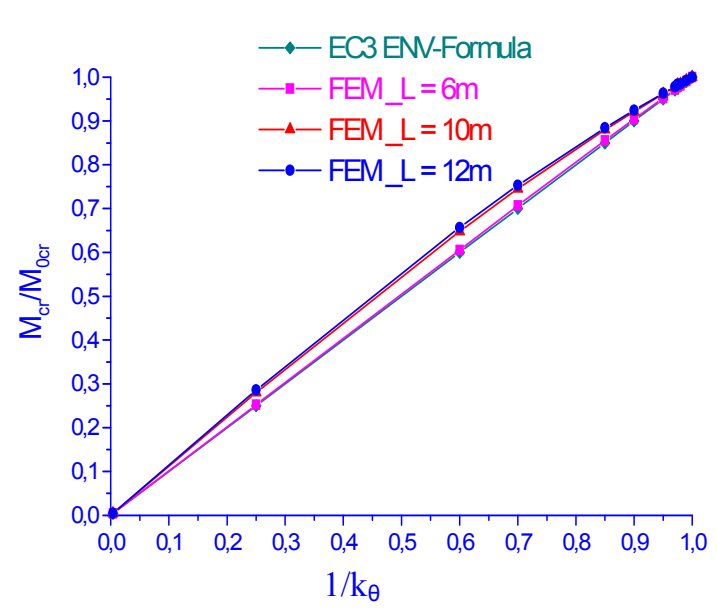

(a) Results for IPE 300

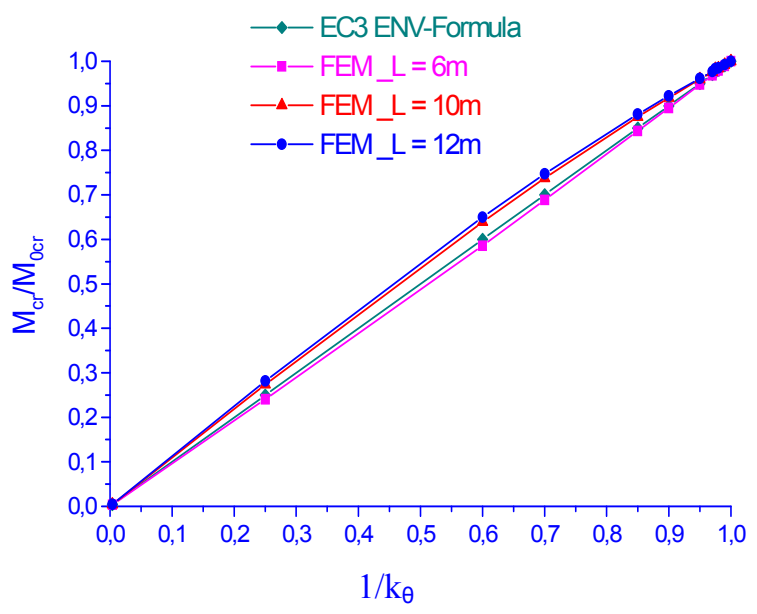

(b) Results for IPE 360 


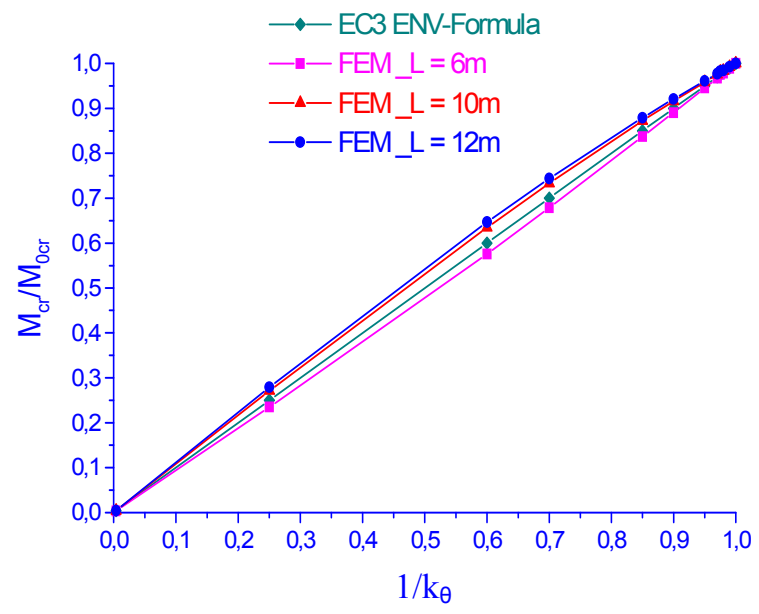

(c) Results for IPE 400

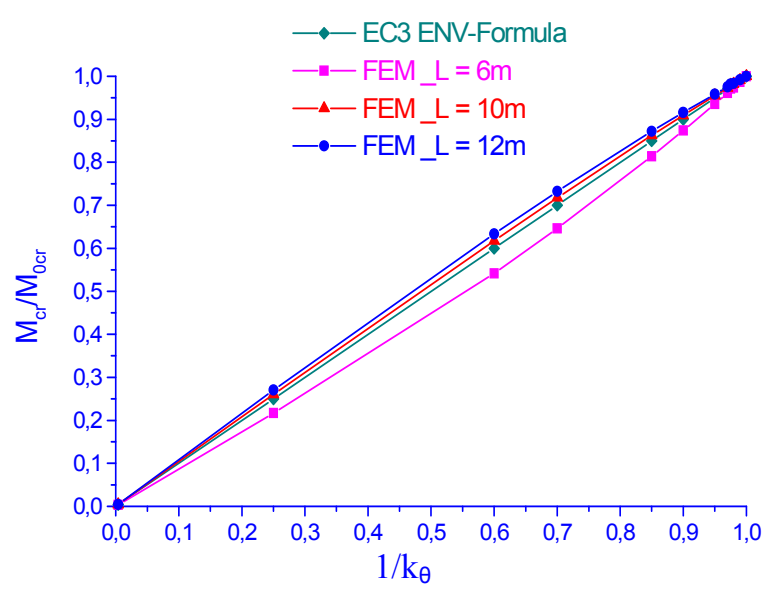

(d) Results for IPE 500

Figure 7. Results from FEM and Eq. 10 for a Concentrated Load at Mid-span

It is worth noting from Figure 6 and Figure 7 that, the closer the $M_{c r} / M_{0 c r}$ graphs to the straight line, the more accurate the formula (7). Therefore it can be seen from the figures that, for both load cases and for all IPE cross-sections and lengths considered in this study, the graphs of $M_{c r} / M_{0 c r}$ obtained from FEM analysis are particularly close to the ones obtained from the proposed analytical expression Eq. 10, in which the torsional restraint coefficient $k_{\theta}$ has been introduced. In other words, comparison of the cases performed in this analysis revealed that an acceptable small difference exists between analytical and numerical results (errors are within about 10\%). Therefore, there is quite good agreement between the results given by the proposed analytical formula and the numerical results of the FEM approaches.

\section{REQUIRED CONNECTION TO ENSURE SUFFICIENT RESTRAINT LEVEL}

Depending on the degree of lateral bending and torsional restraints developed, a connection can be classified as simple, partial or full restraint connection. Using the analytical model developed in section 3.1, it is now possible to evaluate the lateral bending and torsional restraints for any beam end connection, therefore its classification can be made.

If a lateral bending restraint of a connection results in a reduction of less than $10 \%$ of $M_{c r}$ from $M_{0 c r}$ for full restraint, then it can be assumed as full lateral bending restraint connection. However, if it results in more than $10 \%$ drop of $M_{c r}$ from $M_{0 c r}$, then it is considered as partial bending restraint connection. Similarly, if a connection torsional restraint results in less than $10 \%$ drop of $M_{c r}$ from $M_{0 c r}$, then full torsional restraint connection can be assumed, otherwise, it is considered as partial tortional restraint connection.

The interaction between the effects of $k_{z}$ and $k_{\theta}$ on the elastic critical moment has not been included in this study. Therefore, in order to classify a connection, it is clear that the effects of lateral bending and torsional restraints have been considered independently in the analysis. Thus, when varying the values of $k_{z}$, the torsional restraint has been considered as full torsional restraint $\left(k_{\theta}=1\right)$. When varying the values of $k_{\theta}$, the lateral bending restraint has been considered as simple restraint $\left(k_{z}=1\right)$. 
Finite elements analyses have been performed to verify the accuracy of Eqs. 6 and 7. For beams with IPE profiles subjected to equal end moments, uniformly distributed loads or, a concentrated point load at the mid span acting at the shear centre, the results show that Eq. 6 can be reasonably applied to evaluate the lateral bending restraint coefficient $k_{z}$.

The analyses also show that for beams with IPE profiles subjected to uniformly distributed loads or, a concentrated point load at the mid span acting at the shear centre and for $k_{z}=1$, Eq. 7 can be satisfactory applied to simulate the effect of the torsional restraint of the end support $k_{\theta}$.

It can be seen from Figure 3, that for the case of beams subjected to equal end moments, $10 \%$ drop in the value of the elastic critical moment $M_{c r}$ against $M_{0 c r}$ for full restraint, is obtained for a value of $k_{z}=0,53$. For the case of uniformly distributed loads, Figure 4 , shows that $10 \%$ reduction in the value of $M_{c r}$ from $M_{0 c r}$ for full restraint, corresponds to $k_{z}=0,56$. Figure 5 shows that for a beam subjected to a concentrated point load at the mid-span and for $k_{z}=0,577$, the corresponding value of the elastic critical moment $M_{c r}$ is reduced by $10 \%$ compared to $M_{0 c r}$ for full restraint. It can also be seen that, for the same percentage reduction in $M_{c r}$, the corresponding values of $k_{z}$ are strongly dependent on the loading type.

According to the results obtained from the proposed expressions of $k_{z}$ and $k_{\theta}$ given in section 3.1 , it is recommended that if the percentage drop in the value of the elastic critical moment $M_{c r}$ against $M_{c r}$ for full restraint remains within $10 \%$, then full restraint may be assumed. Therefore, for lateral bending restraint coefficients $k_{z}$ ranging from 0,5 to 0,53 (for equal end moments), from 0,5 to 0,56 (for uniformly distributed loads) and from 0,5 to 0,577 (for a concentrated point load at mid-span), the end lateral bending restraint may be assumed as full lateral bending restraint $\left(k_{z}=0,5\right)$. For each load case, the minimum lateral flexural stiffness value of the end support $k_{v^{\prime}}$ required to assume full lateral restraint of the support, can be obtained from Eq. 6 .

Figure 6 and Figure 7 show the values of $\frac{1}{k_{\theta}}$ for percentage drops in the value of the elastic critical moment $M_{c r}$, against $M_{0 c r}$ for full torsional restraint. When examining Figure 6. and Figure 7, it can be revealed from analytical and FEM results that for $\frac{1}{k_{\theta}}=0,9$, the corresponding value of $M_{c r} / M_{0 c r}$ is 0,9 . Therefore, for all IPE cross-sections, beam lengths and load cases performed in this analysis, $10 \%$ reduction in the value of $\frac{1}{k_{\theta}}$, results in $10 \%$ drop in the value of $M_{c r}$ against $M_{0 c r}$ for full torsional restraint.

According to results in section 3.1, for IPE cross-sections under uniformly distributed loads or a concentrated point load at mid span acting at the shear centre, Eq. 7 provides values of end torsional restraint coefficients $k_{\theta}$ that are in very good agreement with the FEM results. 
It can be seen from Figure 6, Figure 7 and Eq. 7 that for 10\% drop in the value of the elastic critical moment $M_{c r}$ against $M_{0 c r}$ for full torsional restraint, it results in a value of $\frac{1}{k_{\theta}}=0,9$, which corresponds to a value of the torsional stiffness of the support $K_{\Theta}=21,3 G I_{t} / L$. Thus, for $\frac{K_{\Theta}}{G I_{t} / L}=21,3$ (ratio of the torsional stiffness of the supports to its beam), the value of the elastic critical moment is $M_{c r}=0,9 M_{0 c r}$.

From these results, it is recommended to assume that the torsional stiffness of the connection is acceptable and may be considered as full torsional restraint, if it results in no more than $10 \%$ drop in the value of $M_{c r}$ for full restraint. Therefore, if it is proved that the ratio of the torsional stiffness of a connection $K_{\Theta}$ to its beam $G I_{t} / L$ is at least equal to 21,3 , then it is recommended to assume full restraint connection, as $M_{c r}$ will be $90 \%$ of $M_{0 c r}$ for rigid torsional end support.

\section{CONCLUSIONS}

When dealing with lateral torsional buckling, modern design standards require the computation of the elastic critical moment, which mainly depends on the moment distribution along the beam and on the end supports restraints. One of the most commonly used general formulae to estimate elastic critical moments in steel beams prone to LTB is the so-called 3-factor formula, which is included in the ENV version of Eurocode 3 [5].

This paper presents a review of EC3 ENV approach and its limitations with regards to lateral bending and torsional restraints of the end supports. Based on these limitations, the paper has presented new expressions for estimating the actual degree of lateral bending restraint $k_{z}$ and torsional restraint $k_{\theta}$ of the end supports. The values of the coefficients $k_{z}$ and $k_{\theta}$ obtained from the proposed expressions, are introduced in the general formulae that estimates the elastic critical moment. The influence of the lateral bending and torsional restraint on the lateral-torsional buckling of IPE beams with various cross-sections, different loading conditions and lengths has been investigated using analytical and FEM approach. Comparison between these two approaches allows to show the accuracy of the proposed $k_{z}$ and $k_{\theta}$ expressions.

For beams subjected to uniformly distributed loads or a concentrated load at mid-span applied at the shear centre, the results of the variation of $M_{c r}$ against $k_{z}$, obtained from EC3 (ENV) formula for $k_{z}$ varying from 0,5 to 1,0 are in very good agreement with those computed from FEM. The results of variation of $M_{c r} / M_{0 c r}$ versus $\frac{1}{k_{\theta}}$ computed from FEM are quite close to those obtained from EC3 (ENV) formula. Finally the following can be concluded from this study:

(i) Eq. 6 and Eq. 7 can be reasonably applied to evaluate lateral bending and torsional restraints of end supports.

(ii) For beams subjected to equal end moments with $k_{z}=0,5$, it is recommended that the value of coefficient $C_{1}$ be taken as 1,05 , instead of 1,00 . 
(iii) Full lateral and torsional restraint of end supports may be assumed if it results in less than a $10 \%$ drop in the value of elastic critical moment $M_{c r}$ against full torsional restraint moment $M_{0 c r}$.

(iv) Full lateral bending restraint at supports may be assumed for beams subjected to equal end moments, if $k_{z} \leq 0,53$, for uniformly distributed loads if $k_{z} \leq 0,56$ and for a concentrated point load at mid span if $k_{z} \leq 0,577$.

(v) To assume full torsional restraint of end supports, it is necessary that the ratio between the torsional stiffness of the supports and of the beam $\frac{K_{\Theta}}{G I_{t} / L}$ be at least 21,3 .

\section{ACKNOWLEDGMENT}

The authors gratefully acknowledge the support provided by the ArGEnCo Department at Liège University (Belgium).

\section{REFERENCES}

[1] AISC LRFD 1986. American Institute of Steel Construction (AISC). Load and resistance factor design. Chicago: AISC; 1986.

[2] AISC LRFD 1994. American Institute of Steel Construction (AISC). Load and resistance factor design. Chicago: AISC; 1994.

[3] BS 5950-1. Structural use of steelwork in buildings. Code of practice for design. Rolled and welded sections. British Standards Institution; 2000.

[4] EC3 2005. European Committee for Standardization. Eurocode 3: Design of steel structures, Part 1-1: General rules and rules for buildings (EN 1993-1-1). Brussels; May 2005.

[5] EC3 1992. European Committee for Standardization. Eurocode 3: Design of steel structures, Part 1-1: General rules and rules for buildings. (ENV 1993-1-1). Brussels; 1992.

[6] Trahair, N.S., "Multiple Design Curves for Beam Lateral Buckling", Stability and Ductility of Steel Structures, T. Usami and Y. Itoh (Eds.), Pergamon, 1998.

[7] Serna, M.A., Lopez, A., Puente, I. and Yong, D.J., "Equivalent Uniform Moment Factors for Lateral-torsional Buckling of Steel Members", Journal of Constructional Steel Research, Vol. 62, pp. 566-580, 2006.

[8] Galéa, Y., "Moment Critique de Déversement élastique de Poutres Fléchies", Presentation du logiciel LTBEAM. Revue de la Construction Métallique. Vol. 2, CTICM 2003.

[9] Flint, A.R., "The Influence of Restraints on the Stability of Beams", The Structural Engineer, Vol. 29, pp. 235-246, September 1951.

[10] Schmidt, L.C., "Restraints Against Elastic Lateral Buckling”, J. of Eng. Mech. Div., ASCE, Vol. 91, No. EM6, pp. 1-10, December 1965.

[11] Bose, B., 'The Influence of Torsional Restraint Stiffness at Supports on the Buckling Strength of Beams", The Structural Engineer, pp. 69-74, December 1982.

[12] Bennetts, I.D., Thomas, I.R. and Grundy, P., "Torsional Stiffness of Shear Connections", Preprints, Metal Structures Conference, Institution of Engineers, pp.-102, Australia, 1981.

[13] Grundy, P., Murray, A.W. and Bennetts, I.D., "Torsional Rigidity of Standard Beam-to-Column Connections", Preprints, Metal Structures Conference, Institution of Engineers, Australia, pp.-164, 1983.

[14] ECCS Technical Committee 8- Stability, 2006. European Convention for Constructional Steelwork, Rules for Member Stability in EN 1993-1-1. Background documentation and design guidelines, No. 119, 2006. 